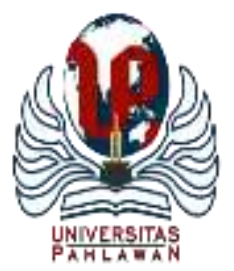

Edukatif : Jurnal Ilmu Pendidikan Volume 3 Nomor 6 Tahun 2021 Halm 3748 - 3757

EDUKATIF: JURNAL ILMU PENDIDIKAN

Research \& Learning in Education

https://edukatif.org/index.php/edukatif/index

\title{
Persepsi Guru Sekolah Dasar terhadap Integrasi Budaya pada Pembelajaran Bahasa Indonesia
}

\author{
Rani Darojah \\ Pendidikan Guru Sekolah Dasar, Universitas Terbuka, Indonesia \\ E-mail : ranidarojah@ecampus.ut.ac.id
}

\begin{abstract}
Abstrak
Tujuan penelitian ini untuk mengetahui persepsi guru SD di Kecamatan Rembang Kabupaten Purbalingga terhadap pengintegrasian budaya dalam pembelajaran Bahasa Indonesia. Meskipun banyak sekali penelitian terkait pengintegrasian budaya ke dalam pembelajaran Bahasa Indonesia, namun dalam penelitian ini memiliki karaktersistik yang berbeda yaitu konteks budaya di wilayah Perdikan Cahyana. Pengumpulan data dilakukan melalui kuesioner dan wawancara yang diberikan kepada guru SD di kecamatan Rembang, Kabupaten Purbalingga. Selanjutnya data tersebut dianalisis secara kuantitatif dan kualitatif. Hasil penelitian menunjukkan bahwa integrasi budaya dalam konteks wilayah Perdikan Cahyana ke dalam pembelajaran Bahasa Indonesia yaitu: 1) dapat membantu peserta didik meningkatkan kompetensi linguistik dan komunikatif siswa dalam komunikasi multikultural; 2) menambah sumber belajar yang dapat digunakan untuk menanamkan budaya dalam pembelajaran Bahasa Indonesia; 3) menambah beragam cara untuk mengintegrasikan budaya dalam pembelajaran bahasa Indonesia; dan 4) diperlukan dukungan, saran dan tindakan lebih lanjut agar integrasi budaya ke dalam pembelajaran bahasa Indonesia menjadi lebih efektif.
\end{abstract}

Kata Kunci: Perdikan Cahyana, budaya, Bahasa Indonesia.

\begin{abstract}
The purpose of this study was to determine the perceptions of elementary school teachers in Rembang Subdistrict, Purbalingga Regency on the integration of culture in language learning. Although there were many studies related to the integration of culture into language learning, this study had different characteristics, namely the cultural context in the "Perdikan Cahyana" area. Data collection was carried out through a questionnaire and interview to elementary school teachers. Furthermore, the data were analyzed quantitatively and qualitatively. The results showed that the integration of culture into language learning were able to: 1) improve students' linguistic and communicative competence in multicultural communication; 2) provide learning resources that can be used to instill culture in language learning; 3) give various ways to integrate culture in language learning; in addition, 4) the results of this research need support, suggestions and further actions to the effective integration of culture into Indonesian language learning.
\end{abstract}

Key words: Perdikan Cahyana, Culture, Indonesian Language

Copyright (c) 2021 Rani Darojah

$\bowtie$ Corresponding author

Email : ranidarojah@ecampus.ut.ac.id

DOI : https://doi.org/10.31004/edukatif.v3i6.1202

ISSN 2656-8063 (Media Cetak)

ISSN 2656-8071 (Media Online) 
3749 Persepsi Guru Sekolah Dasar terhadap Integrasi Budaya pada Pembelajaran Bahasa Indonesia - Rani Darojah

DOI: https://doi.org/10.31004/edukatif.v3i6.1202

\section{PENDAHULUAN}

Bahasa merupakan salah satu unsur kebudayaan (Murdiyati, 2020; Susanto, 2020; Susanto et al., 2019; Triyanto et al., 2019), hal tersebut memungkinkan manusia dapat memanfatkannya untuk memperoleh dan mempelajari beragam pengalaman yang diperolehnya melalui kegiatan interaksi dan komunikasi dengan kelompok masyarakat dan lingkunggan sekitarnya. Bahasa sebagai alat komunikasi, memungkinkan seseorang dapat diterima di kelompok sosialnya, sehingga dapat ikut serta dalam beragam aktititas kelompok sosial masyarakat yang dimilikinya. serta dapat melakukan semua. Oleh sebab itu, dapat dikatakan bahwa bahasa memungkinkan terjadinya integrasi yang sempurna bagi setiap individu dengan masyarakatnya (Fauziyah M., 2015).

Bagi bangsa Indonesia, bahasa Indonesia merupakan bahasa resmi sekaligus bahasa pemersatu bagi masyarakat Indonesia yang majemuk. Bahasa Indonesia wajib dikuasai oleh semua masyarakat Indonesia. melalui pembelajaran di sekolah, bahasa Indonesia dijadikan sebagai salah satu mata pelajaran yang wajib diikuti oleh peserta didik dari jenjang tingkat dasar sampai tingkat perguruan tinggi. Sebagaimana dikatakan oleh Arianti (2021), pembelajaran bahasa Indonesia merupakan pelajaran yang sangat penting \& wajib bagi masyarakat Indonesia. Oleh sebab itu, sebagai warga negara yang baik \& benar harus mampu mengetahui dan menerapkan pembelajaran bahasa Indonesia sesuai dengan tuntutan yang dibutuhkan.

Bahasa dan budaya memiliki hubungan yang sangat erat dan berlanjut secara terus-menerus (Fauziah, 2015). Hubungan tersebut dapat dilihat dimana bahasa berperan sebagai sumber budaya, sedangkan berbahasa sebagai praktik budaya (Suyitno, 2017). Selanjutnya budaya juga juga memiliki peran penting dalam pembelajaran bahasa. Thanasoulas (2001), menyatakan bahwa budaya dapat meningkatkan dan memperkaya kompetensi komunikatif peserta didik serta mengarahkan mereka pada empati dan rasa hormat terhadap budaya yang berbeda dan meningkatkan objektivitas dan wawasan budaya yang mereka miliki. Sehingga kompetensi budaya dianggap sebagai salah satu kompetensi komunikatif atau keterampilan bahasa ke-5 (Vernier et al. 2008; Ghafor, 2020). Selain itu, budaya merupakan suatu identas bangsa, sehingga budaya harusnya menjadi hal utama yang harus diperkenalkan ketika seseorang ingin belajar tentang bangsa Indonesia, termasuk belajar bahasa Indonesia (Yanuar et al., 2017). Pembelajar bahasa juga akan melihat bagaimana bahasa dan budaya saling berfusi dan berkaitan, dan ia juga akan semakin memahami lingkungannya serta mengerti bagaimana bahasa dan budaya mempengaruhi proses penguasaan bahasa tersebut (Arifin, 2018).

Karena sifat hubungan antara budaya dan bahasa dalam pembelajaran bahasa, para peneliti menyarankan untuk menanamkan budaya dalam pembelajaran bahasa. Namun, dalam praktiknya, cara untuk mengintegrasikan unsur budaya ke dalam pembelajaran bahasa masih sering menjadi persoalan. Terlebih lagi dalam mengintegrasikan unsur budaya lokal bangsa Indonesia yang masih banyak belum digali oleh para peneliti. Menurut Panjaitan, dkk (2014:113) agar eksistensi budaya tetap utuh, generasi penerus bangsa perlu ditanamkan rasa cinta terhadap budaya daerah, salah satu cara yang dapat dilakukan guru adalah dengan mengimplementasikan kearifan budaya lokal dalam pembelajaran di sekolah. Menurut Novitawati (2021), penanaman budaya harus dikenalkan kepada anak sejak dini sebagai bentuk pelestarian kepada generasi penerus. Selain itu, menurut Prihastari, dkk (2021) penanaman budaya lokal pada pendidikan dapat menanamkan identitas dan jati diri bangsa. Oleh karena itu, penelitian tentang integrasi budaya lokal ke dalam kelas bahasa Indonesia untuk membekali para siswa tentang pemahaman, keterampilan dan sikap terhadap budaya lokal yang mereka miliki menjadi praktis dan perlu. Temuan penelitian ini akan berkontribusi pada kesenjangan penelitian teoritis di bidang budaya dan pengajaran bahasa.

Secara teoritis, budaya merupakan bagian integral dalam proses belajar mengajar bahasa dan merupakan faktor yang berpengaruh dalam keberhasilan pembelajaran bahasa. Suhaeb (2010) menyatakan bahwa unsur-unsur budaya masyarakat pemakai bahasa harus menjadi bagian integral dari materi pengajaran 
bahasa. Namun, berdasarkan hasil observasi dan wawancara yang dilakukan oleh peneliti, para guru di wilayah Perdikan Cahyana belum berupaya untuk mengintegrasikan budaya lokal yang ada ke dalam pembelajaran bahasa. Hal ini sangat memungkinkan terjadi karena dalam pembelajaran bahasa para guru sering kali berbeda pendapat mengenai unsur-unsur budaya masyarakat yang akan ikut diajarkan kepada para peserta didik (Suhaeb, 2010). Adapun muatan budaya yang diberikan kepada siswa terbatas hanya pada budaya nasional dan budaya daerah yang berasal dari daerah lain. Tentunya hal tersebut tidak sesuai dengan anjuran pemerintah agar dapat menanamkan pengetahuan budaya lokal terhadap siswa semenjak dini sebagai upaya untuk menggali identitas suatu wilayah tertentu dan akan memperkaya budaya nasional bangsa Indonesia. Oleh sebab itu, penelitian ini diharapkan dapat membantu peneliti menemukan bukti ilmiah terkait dengan tentang persepsi guru sekolah dasar di wilayah Perdikan Cahyana terhadap integrasi budaya lokal dalam pembelajaran bahasa.

Tujuan dari penelitian ini adalah untuk mengetahui (1) persepsi guru SD terhadap budaya dan perannya di kelas bahasa, (2) persepsi mereka tentang integrasi budaya mereka di kelas bahasa, dan (3) Manfaat dan kendala yang mereka hadapi ketika mengintegrasikan budaya di kelas bahasa.

\section{METODE PENELITIAN}

Penelitian ini menggunakan desain penelitian deskriptif dengan menggunakan kuesioner dan wawancara untuk mendapatkan data mengenai persepsi guru Sekolah Dasar terhadap integrasi budaya lokal ke dalam pembelajaran Bahasa Indonesia. (Moleng, 2012) mendeskripsikan metode penelitian kualitatif sebagai prosedur penelitian yang menghasilkan data deskriptif berupa data-data dan perilaku yang diamati. Penelitian akan dilakukan pada 96 guru Sekolah Dasar yang bekerja di 16 Sekolah Dasar Kecamatan Rembang, Purbalingga. Kuesioner dan wawancara yang digunakan untuk mengetahui persepsi guru Sekolah Dasar tentang istilah budaya lokal dan perannya dalam pembelajaran Bahasa Indonesia, persepsi mereka tentang penanaman budaya dalam pembelajaran bahasa Indonesia, dan kelebihan dan kekurangan menanamkan budaya dalam pembelajaran Bahasa Indonesia.

Kuesioner berisi pertanyaan yang dirancang menggunakan skala linkert dengan lima kriteria penilaian, yaitu 1 (sangat tidak setuju), 2 (tidak setuju), 3 (netral), 4 (setuju), dan 5 (sangat setuju) dan pertanyaan terbuka. Kuesioner pertama kali diberikan kepada 20 guru SD sebagai tahap uji coba. Setelah diuji validitas dan reliabilitas instrumen tersebut, selanjutnya kuesioner diberikan kepada 96 guru SD. Sementara itu, wawancara dilakukan setelah data kuesioner diperoleh oleh peneliti. Wawancara bertujuan untuk memperjelas dan mengkonsolidasikan data, sehingga wawancara hanya dilakukan kepada peserta yang datanya perlu diklarifikasi dan dikonsolidasikan dan/atau kepada guru yang berpengalaman dengan harapan mendapatkan informasi yang lebih mendalam. Kegiatan wawancara dilakukan sekitar 30 menit secara virtual. Selama wawancara, peneliti mencatat jawaban dan komentar para guru dan mengkonfirmasi jawaban para guru dengan mengulangi beberapa tanggapan mereka.

\section{HASIL DAN PEMBAHASAN PENELITIAN}

\section{Persepsi Guru terhadap Istilah Budaya lokal dan Perannya dalam Pembelajaran Bahasa di Sekolah Dasar}

Berdasarkan hasil kuesioner yang ditunjukan pada Tabel 1, diketahui bahwa rerata skor angket persepsi guru tentang budaya adalah $\mathrm{M}=3,87$. Hal ini menunjukkan bahwa guru setuju dengan semua definisi budaya lokal yang disebutkan di dalam kuesioner. 
3751 Persepsi Guru Sekolah Dasar terhadap Integrasi Budaya pada Pembelajaran Bahasa Indonesia - Rani Darojah

DOI: https://doi.org/10.31004/edukatif.v3i6.1202

Tabel 1. Rerata Skor Persepsi Guru tentang Istilah Budaya Lokal

\begin{tabular}{llllll}
\hline & $\mathrm{N}$ & Min. & Max & Mean & SD \\
\hline General mean & 96 & 2 & 5.00 & 3.87 & 0.682 \\
\hline
\end{tabular}

Persepsi guru terhadap setiap item akan dijelaskan secara rinci pada tabel 4.2 di bawah ini.

Tabel 2. Persepsi Guru tentang Istilah Budaya

\begin{tabular}{llllll}
\hline Item & $\mathrm{N}$ & Min. & Max & Mean & SD \\
\hline Budaya adalah produk budaya & 96 & 2 & 5 & 3.84 & 0.663 \\
\hline Budaya adalah praktik budaya & 96 & 2 & 5 & 3.92 & 0.714 \\
\hline Budaya adalah perspektif budaya & 96 & 2 & 5 & 3.85 & 0.703 \\
\hline Budaya adalah komunitas budaya & 96 & 2 & 5 & 3.87 & 0.670 \\
\hline Budaya adalah pribadi budaya & 96 & 2 & 5 & 3.89 & 0.661 \\
\hline
\end{tabular}

Pada tabel 2. di atas menunjukkan bahwa guru SD di kecamatan Rembang, kabupaten Purbalingga setuju mendefinisikan budaya sebagai: 1) produk budaya termasuk artefak, tempat, institusi, dan bentuk seni; 2) praktik budaya termasuk perilaku budaya dan bahasa sebagai operasi, tindakan, skenario, dan kehidupan; 3) perspektif budaya meliputi persepsi, keyakinan, nilai, sikap serta pandangan etik (luar) dan emic (dalam); 4) komunitas budaya termasuk komunitas nasional, komunitas dan hubungan yang hidup berdampingan; dan 5) sebagai pribadi budaya termasuk konsep identitas dan sejarah kehidupan.

Namun demikian, berdasarkan hasil wawancara ada beberapa guru yang memiliki pendapat berbeda terkait istilah "budaya". Mereka menganggap bahwa budaya sebagai keyakinan agama, segala sesuatu yang berhubungan dengan tradisi, adat istiadat, percakapan, cara umum yang diterima, peradaban, budidaya (pertanian).

Selanjutnya terkait dengan peran budaya dalam pembelajaran Bahasa di Sekolah Dasar, para guru setuju bahwa budaya khususnya budaya lokal sangat penting untuk diintegrasikan di dalam pembelajaran Bahasa di Sekolah Dasar. Hal tersebut ditunjukan dalam tabel 3. di bawah ini.

Tabel 3. Rerata Skor Persepsi Guru tentang Peran Budaya Lokal dalam Pembelajaran Bahasa Indonesia

\begin{tabular}{llllll}
\hline & $\mathrm{N}$ & Min. & Max & Mean & SD \\
\hline General mean & 96 & 1 & 5.00 & 4.30 & 0.937 \\
\hline
\end{tabular}

Tabel 3 menunjukkan bahwa skor rata-rata dari kuesioner untuk persepsi guru SD terhadap peran budaya di kelas bahasa adalah $\mathrm{M}=4.3$. Nilai rata-rata menunjukkan bahwa guru-guru ini sangat setuju bahwa budaya memainkan peran penting dalam kelas bahasa Indonesia. Budaya lokal perlu diintegrasikan dalam materi pembelajaran siswa di sekolah dasar sebagai wujud menghargai dan melestarikan budaya lokal di sekitar siswa. Sehingga diharapkan siswa dapat mengenali dan memahami budaya lokal (Samsiyah, 2020).

\section{Persepsi Guru tentang Penanaman Budaya dalam Pembelajaran Bahasa Indonesia}

Temuan hasil dari kuesioner yang diberikan kepada para guru SD di kecamatan Rembang, kabupaten Purbalingga mengungkapkan bahwa mereka menggunakan buku teks, bahan ajar yang mereka kembangkan sendiri, dan pemahaman mereka untuk mengajarkan budaya di kelas bahasa. Hal tersebut ditunjukkan pada tabel 4 di bawah ini. 
3752 Persepsi Guru Sekolah Dasar terhadap Integrasi Budaya pada Pembelajaran Bahasa Indonesia - Rani Darojah

DOI: https://doi.org/10.31004/edukatif.v3i6.1202

Tabel 4. Persepsi guru tentang penanaman budaya dalam pembelajaran Bahasa Indonesia

\begin{tabular}{lllllll}
\hline Item & $\mathrm{N}$ & Min. & Max & Mean & SD \\
\hline Guru hanya menggunakan buku teks. & 96 & 1 & 5 & 2.79 & 1.156 \\
\hline $\begin{array}{l}\text { Guru menggunakan buku teks dan bahan ajar yang mereka } \\
\text { susun. }\end{array}$ & 96 & 1 & 5 & 3.43 & 1.008 \\
$\begin{array}{l}\text { Guru menggunakan buku teks, bahan ajar yang mereka } \\
\text { susun, dan pemahaman mereka. }\end{array}$ & 96 & 2 & 5 & 4.08 & 0.714 \\
\hline
\end{tabular}

Sementara temuan dari wawancara menunjukan bahwa semua guru SD di kecamatan Rembang, kabupaten Purbalingga menambahkan internet sebagai sumber materi yang dapat digunakan guru untuk menanamkan budaya di kelas bahasa. Selain internet, peserta juga menyebutkan sumber lain yang dapat digunakan guru sebagai bahan integrasi budaya seperti film, video, koran, dan media lainnya.

\section{Persepsi Guru tentang Konten Budaya yang dapat diintegrasikan dalam Pembelajaran Bahasa Indonesia}

Tabel 5. Persepsi guru tentang konten budaya yang dapat diintegrasikan dalam pembelajaran bahasa

\begin{tabular}{llllll}
\hline Item & $\mathrm{N}$ & Min. & Max & Mean & SD \\
\hline Menyediakan informasi budaya untuk siswa & 96 & 3 & 5 & 4.02 & 0.695 \\
\hline Mengembangkan perilaku budaya siswa & 96 & 3 & 5 & 4.02 & 0.695 \\
\hline $\begin{array}{l}\text { Meningkatkan kemampuan siswa dalam } \\
\text { mengintepretasikan budaya }\end{array}$ & 96 & 2 & 5 & 3.97 & 0.730 \\
\hline $\begin{array}{l}\text { Mengembangkan kemampuan individu siswa terkait dengan } \\
\text { cara pandang dunia dan kompetensi personal }\end{array}$ & 96 & 2 & 5 & 3.90 & 0.851 \\
\hline
\end{tabular}

Berdasarkan hasil kuesioner yang terlihat pada tabel di atas, menunjukkan bahwa guru setuju terhadap semua konten budaya yang disebutkan dalam kuesioner, yaitu: 1) dapat memberikan informasi budaya siswa, 2) mampu mengembangkan perilaku budaya siswa, 3) dapat meningkatkan interpretasi budaya siswa, dan 4) dapat mengembangkan cara pandang siswa terhadap dunia dan kepribadian mereka. Selanjutnya, temuan dari wawancara menunjukkan bahwa budaya yang diberikan seharusnya juga dapat memberikan kesempatan siswa untuk mengembangkan kemampuan analisis yaitu menganalisis hubungan bahasa dan budaya yang saling terkait, dan membebaskan siswa dari prasangka budaya dan etnosentrisme, dan mengembangkan pandangan sosiokultural siswa. Pembelajaran budaya disekolah dasar akan dapat menjadikan siswa semakin cinta terhadap budaya bangsa dan Negara, di samping itu sekolah dapat menunjukkan kepada masyarakat sekitar bahwa sekolah ikut serta melestarikan budaya lokal dengan memberikan pembelajaran berbagai budaya lokal untuk menanamkan rasa nasionalisme kepada siswanya (Aswasulasikin, dkk. 2020).

\section{Persepsi Guru tentang fungsi Bahasa dalam Pembelajaran Bahasa Indonesia berbasis budaya}

Serupa dengan hasil konten budaya, semua guru SD setuju dengan fungsi bahasa yang disebutkan di dalam pertanyan kuesioner, yaitu: 1) bahasa yang digunakan siswa untuk berpartisipasi dalam pengalaman budaya, 2) untuk menggambarkan pengalaman budaya, 3) untuk mengidentifikasi, menjelaskan dan membenarkan perspektif budaya dan untuk membandingkan dan mengkontraskannya dengan perspektif dari budaya siswa dan budaya lain, dan 4) untuk mengekspresikan pemikiran siswa.

Tabel 6. Persepsi Guru tentang fungsi Bahasa dalam dalam Pembelajaran Bahasa Indonesia berbasis budaya

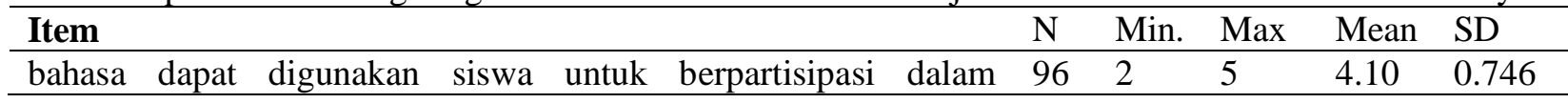


3753 Persepsi Guru Sekolah Dasar terhadap Integrasi Budaya pada Pembelajaran Bahasa Indonesia - Rani Darojah

DOI: https://doi.org/10.31004/edukatif.v3i6.1202

\begin{tabular}{lllllll}
\hline pengalaman budaya & & & & \\
\hline $\begin{array}{l}\text { bahasa dapat digunakan untuk menggambarkan pengalaman } \\
\text { budaya. }\end{array}$ & 26 & 5 & 3.95 & 0.717 \\
\hline $\begin{array}{l}\text { bahasa dapat digunakan siswa untuk mengidentifikasi, } \\
\text { menjelaskan dan membenarkan perspektif budaya dan juga untuk } \\
\text { membandingkan dan mengkontraskannya dengan perspektif dari } \\
\text { budaya individu itu sendiri dan budaya lain. }\end{array}$ & & 5 & 3.95 & 0.717 \\
$\begin{array}{l}\text { bahasa dapat digunakan siswauntuk mengekspresikan pemikiran } \\
\text { mereka }\end{array}$ & 36 & 5 & & & \\
\hline
\end{tabular}

Sementara dalam wawancara, guru berbagi bahwa guru harus menyediakan fungsi bahasa siswa untuk membantu mereka menolak untuk melakukan sesuatu, untuk berbagi perasaan mereka dan untuk mendorong seseorang untuk menghibur seseorang.

\section{Persepsi Guru tentang Tujuan Pembelajaran budaya dalam pembelajaran Bahasa Indonesia}

Untuk hasil pengintegrasian budaya ke dalam pembelajaran bahasa, guru setuju bahwa tujuan pembelajaran budaya adalah agar siswa dapat: 1) mendemonstrasikan penampilan perilaku atau kompetensi budayanya, 2) pemahamannya terhadap informasi yang disajikan, 3) kemampuan membuat penjelasan budaya, dan 4) ekspresi kesadaran dirinya. Selanjutnya dalam wawancara, guru juga memodifikasi bahwa tujuan awal pembelajaran budaya adalah agar siswa dapat berhasil dalam komunikasi multikultural

Tabel 7. Persepsi Guru tentang Tujuan Pembelajaran budaya dalam pembelajaran Bahasa Indonesia

\begin{tabular}{|c|c|c|c|c|c|}
\hline Item & $\mathrm{N}$ & Min. & Max & Mean & SD \\
\hline $\begin{array}{l}\text { mendemonstrasikan penampilan perilaku atau kompetensi } \\
\text { budayanya. }\end{array}$ & 96 & 3 & 5 & 3.92 & 0.696 \\
\hline $\begin{array}{l}\text { mendemonstrasikan pemahamannya terhadap informasi yang } \\
\text { disajikan }\end{array}$ & 96 & 2 & 5 & 3.72 & 0.686 \\
\hline $\begin{array}{l}\text { mendemonstrasikan kemampuannya dalam membuat penjelasan } \\
\text { suatu budaya. }\end{array}$ & 96 & 2 & 5 & 3.82 & 0.671 \\
\hline mendemonstrasikan ekspresi kesadaran dirinya terhadap budaya & 96 & 3 & 5 & 3.89 & 0.635 \\
\hline
\end{tabular}

Dalam konteks mutualitas nilai-nilai budaya dalam pendidikan bahasa dan sastra menjadi benar-benar tampak, dan penting untuk diimplementasikan karena kebudayaan merupakan tempat tumbuhnya identitas dan kepribadian. Konseptualisasi wawasan budaya dalam pendidikan sebagai jalan menuju terbangunnya genre pendidikan bahasa dan sastra yang khas sekaligus mengisyaratkan pentingnya pendekatan multikultural dalam pelaksanaannya. Semua itu dapat terlaksana apabila materi bahasa dan sastra dalam proses pendidikan dan pembelajaran diperhitungkan sebagai "rumah" pengalaman kemanusiaan (Sayuti, 2016).

\section{Persepsi Guru tentang jenis kegiatan pembelajaran untuk penanaman budaya dalam pembelajaran Bahasa Indonesia}

Tabel 8. Persepsi Guru tentang jenis kegiatan pembelajaran untuk penanaman budaya dalam pembelajaran

\begin{tabular}{lllllll}
\multicolumn{2}{c}{ Bahasa Indonesia } & & & & \\
\hline Item & $\mathrm{N}$ & Min. & Max & Mean & SD \\
\hline $\begin{array}{l}\text { Guru menggunakan kegiatan operasional, ritual, dialog, } \\
\text { permainan peran, pertunjukan, drama, simulasi dan pengalaman } \\
\text { lapangan. }\end{array}$ & 3 & 5 & 3.92 & 0.557 \\
\hline $\begin{array}{l}\text { Guru menggunakan bahan otentik, bahan pedagogis, pengalaman } \\
\text { dan akun pribadi }\end{array}$ & 96 & 3 & 5 & 3.89 & 0.661 \\
\hline
\end{tabular}


3754 Persepsi Guru Sekolah Dasar terhadap Integrasi Budaya pada Pembelajaran Bahasa Indonesia - Rani Darojah

DOI: https://doi.org/10.31004/edukatif.v3i6.1202

\begin{tabular}{llllllll}
\hline Guru menggunakan analisis budaya, penelitian, proyek penelitian & 96 & 2 & 5 & 3.77 & 0.589 \\
\hline $\begin{array}{l}\text { Guru menggunakan refleksi, berbicara terfokus dan menulis } \\
\text { terfokus }\end{array}$ & 96 & 3 & 5 & 5 & 0.608 \\
\hline
\end{tabular}

Temuan dari kuesioner menunjukkan bahwa guru SD menggunakan berbagai jenis kegiatan pembelajaran untuk penanaman budaya seperti 1) kegiatan operasional, ritual, dialog, permainan peran, pertunjukan, drama, simulasi dan pengalaman lapangan; 2) bahan otentik, bahan pedagogis, pengalaman dan akun pribadi; 3) analisis budaya, penelitian, proyek penelitian; dan 4) refleksi, berbicara terfokus dan menulis terfokus. Kemudian temuan dari wawancara menunjukkan bahwa guru dapat memperoleh pengalaman dan pengetahuan budaya siswa; dan mereka dapat menggunakan segala macam kegiatan pembelajaran yang mengandung nilai perspektif budaya.

\section{Persepsi Guru tentang peran guru dalam mengintegrasikan budaya dalam pembelajaran Bahasa Indonesia}

Tabel 9. Persepsi Guru tentang peran guru dalam mengintegrasikan budaya dalam pembelajaran Bahasa Indonesia

\begin{tabular}{|c|c|c|c|c|c|}
\hline Item & $\mathrm{N}$ & Min. & Max & Mean & SD \\
\hline Guru berperan sebagai model dan pelatih & 96 & 2 & 5 & 3.85 & 0.654 \\
\hline Guru berperan sebagai sumber, arbiter dan elisitor & 96 & 2 & 5 & 3.75 & 0.745 \\
\hline $\begin{array}{l}\text { Guru berperan sebagai pembimbing dan pendamping } \\
\text { penelitian }\end{array}$ & 96 & 1 & 5 & 3.97 & 0.632 \\
\hline Guru berperan sebagai pendengar, saksi dan rekan kerja & 96 & 2 & 5 & 3.95 & 0.644 \\
\hline
\end{tabular}

Tabel 9 menunjukkan bahwa ketika mengintegrasikan elemen budaya ke dalam kelas bahasa, guru memainkan banyak peran yang berbeda sebagai model, pelatih, sumber, narasumber, arbiter, elisitor, pemandu, rekan peneliti, pendengar, saksi, dan rekan kerja. Sementara hasil dari wawancara menunjukan para guru menambahkan bahwa guru harus berperan sebagai penilai, dan mereka harus menjadi fasilitator daripada pengontrol.

\section{Manfaat dan kendala yang mereka hadapi ketika mengintegrasikan budaya di kelas bahasa.}

Ketika guru mengintegrasikan elemen budaya ke dalam kelas bahasa, mereka akan menghadapi banyak hambatan seperti yang disebutkan di bawah ini (tabel 10). Namun, guru dalam penelitian ini menunjukkan bahwa siswa dapat memperoleh manfaat dari integrasi budaya. Khususnya, dengan integrasi budaya, siswa dapat mencapai kompetensi linguistik dan komunikatif.

Tabel 10 Manfaat yang mereka hadapi ketika mengintegrasikan budaya di kelas bahasa

\begin{tabular}{llllllll}
\hline Item & $\mathrm{N}$ & Min. & Max & Mean & SD \\
\hline $\begin{array}{l}\text { Integrasi budaya hanya dapat membantu siswa mencapai } \\
\text { kompetensi linguistik }\end{array}$ & 96 & 1 & 5 & 2.79 & 1.156 \\
\hline $\begin{array}{l}\text { Integrasi budaya hanya dapat membantu siswa mencapai } \\
\text { kompetensi komunikatif }\end{array}$ & 96 & 1 & 5 & 2.79 & 1.156 \\
\hline $\begin{array}{l}\text { Integrasi budaya hanya dapat membantu siswa mencapai } \\
\text { kompetensi linguistik dan kompetensi komunikatif }\end{array}$ & 96 & 3 & 5 & 4.02 & 0.609 \\
\hline
\end{tabular}

Dalam wawancara guru mengkonfirmasi efek positif dari budaya pada peningkatan kompetensi linguistik dan komunikatif siswa. Salah satu guru dalam wawancara mengatakan bahwa "dengan memahami 
3755 Persepsi Guru Sekolah Dasar terhadap Integrasi Budaya pada Pembelajaran Bahasa Indonesia - Rani Darojah

DOI: https://doi.org/10.31004/edukatif.v3i6.1202

budaya yang mereka hadapi, siswa dapat secara efektif memperoleh pengetahuan bahasa yang mereka pelajari."

Tabel 11 kendala yang mereka hadapi ketika mengintegrasikan budaya di kelas bahasa

\begin{tabular}{|l|l|l|l|l|l|}
\hline Item & $\mathrm{N}$ & Min. & Max & Mean & SD \\
\hline Guru tidak menyadari pentingnya integrasi budaya di kelas & 96 & 1 & 5 & 3.03 & 0.948 \\
\hline $\begin{array}{l}\text { Guru tidak memiliki kompetensi budaya yang cukup untuk } \\
\text { mengintegrasikan budaya dalam pembelajaran di kelas }\end{array}$ & 96 & 1 & 5 & 3.13 & 0.957 \\
\hline $\begin{array}{l}\text { Guru tidak memiliki kesempatan untuk mengintegrasikan } \\
\text { budaya dalam pembelajaran di kelas }\end{array}$ & 96 & 1 & 5 & 3.36 & 0.967 \\
\hline $\begin{array}{l}\text { Guru berpendapat bahwa siswa dapat belajar budaya setelah } \\
\text { mereka memiliki kompetensi Bahasa }\end{array}$ & 96 & 1 & 5 & 3.08 & 0.900 \\
\hline Kurangnya guru mata pembelajaran bahasa & 96 & 1 & 5 & 3.41 & 0.990 \\
\hline $\begin{array}{l}\text { Pembelajaran budaya secara resmi tidak dimasukan dalam } \\
\text { program pembelajaran bahasa }\end{array}$ & 96 & 1 & 5 & 3.23 & 0.920 \\
\hline $\begin{array}{l}\text { Kurangnya materi pembelajaran yang memiliki muatan } \\
\text { budaya }\end{array}$ & 96 & 1 & 5 & 3.51 & 0.942 \\
\hline $\begin{array}{l}\text { Tidak ada pedoman bagi guru dalam mengintegrasikan } \\
\text { budaya dalam pembelajaran di kelas }\end{array}$ & 96 & 1 & 5 & 3.34 & 1.031 \\
\hline $\begin{array}{l}\text { terdapat pengaruh social budaya dan agama dalam } \\
\text { mengintegrasikan budaya pada pembelajarn di kelas }\end{array}$ & 96 & 2 & 5 & 3.31 & 0.923 \\
\hline $\begin{array}{l}\text { Kurangnya media pembelajaran yang dapat mendukung } \\
\text { pembelajaran bahasa berbasis budaya }\end{array}$ & 96 & 1 & 5 & 3.21 & 0.933 \\
\hline
\end{tabular}

Di antara sepuluh item terkait dengan hambatan yang menghalangi guru untuk mengintegrasikan budaya di kelas bahasa (tabel 11), mereka hanya setuju bahwa kurangnya guru bahasa Indonesia asli dan materi tentang budaya adalah penghalang yang menghambat guru mengintegrasikan budaya di kelas bahasa. Dalam wawancara, guru menambahkan banyak faktor yang menghambat integrasi budaya yaitu terkait dengan faktor guru, siswa dan kebijakan. Mengenai faktor guru, guru berpendapat bahwa kendalanya adalah keterbatasan pengalaman nyata guru, dan pemahaman budaya serta keengganan mereka untuk mengintegrasikannya ke dalam kelas bahasa. Selain itu, guru menganggap bahwa waktu kelas yang terbatas dan gaji yang rendah bagi guru tidak dapat mendorong mereka untuk berusaha sebaik mungkin, terutama untuk melakukan apa yang tidak diwajibkan secara resmi. Keterbatasan waktu dan kurangnya minat menjadi dua kendala yang terkait dengan siswa.

\section{KESIMPULAN}

Dari hasil penelitian, dapat diketahui bahwa (1) guru sangat percaya bahwa budaya memainkan peran penting dalam kelas bahasa dan siswa dapat memperoleh manfaat dari integrasi budaya (siswa dapat mencapai kompetensi linguistik dan komunikatif); (2) guru dapat menggunakan buku teks, bahan yang mereka kembangkan sendiri, dan pemahaman mereka untuk mengajar budaya di kelas bahasa; (3) Guru dapat memberikan informasi budaya siswa, mengembangkan perilaku budaya siswa dan meningkatkan interpretasi budaya siswa; (4) Guru dapat memaksimalkan fungsi bahasa untuk berpartisipasi dan menggambarkan dalam pengalaman budaya; (5) tujuan guru dalam mengintegrasikan budaya di kelas bahasa adalah agar siswa memahami, menjelaskan, menampilkan dan mengekspresikan budaya mereka sendiri; (6) mereka menggunakan berbagai kegiatan pembelajaran untuk penanaman budaya dan (7) guru memainkan peran yang berbeda ketika mengintegrasikan budaya ke dalam kelas bahasa. Namun, ketika mengintegrasikan budaya ke dalam kelas bahasa, guru menghadapi banyak hambatan terkait dengan keterbatasan pengalaman nyata dan pemahaman budaya mereka serta keengganan untuk mengintegrasikannya ke dalam kelas bahasa Indonesia. 
3756 Persepsi Guru Sekolah Dasar terhadap Integrasi Budaya pada Pembelajaran Bahasa Indonesia - Rani Darojah

DOI: https://doi.org/10.31004/edukatif.v3i6.1202

Oleh karena itu, guru harus dilatih untuk memiliki pengalaman budaya yang nyata dan memiliki pemahaman budaya yang mendalam.

\section{DAFTAR PUSTAKA}

Anggraini, Chresty. (2021). Pengembangan Lembar Kerja Peserta Didik (LKPD) Bermuatan Budaya Lokal Untuk Anak Usia Dini. Jurnal Edukatif: Jurnal Ilmu Pendidikan Volume 3 Nomor 6 3500-3508. Https://Doi.Org/10.31004/Obsesi.V6i1.767

Arifin, M.N. (2019). Hubungan Budaya Dan Pengajaran Bahasa. Https://Www.Researchgate.Net/Publication/328052056_

Arianti, D. (2021). Kearifan Lokal Dan Implikasinya Terhadap Pembelajaran Bahasa Indonesia. Linguistik: Jurnal Bahasa Dan Sastra, 6(1), 115-123. Https://Doi: 10.31604/Linguistik.V6i1.115-123

Aswasulasikin, A., Pujiani, S., \& Alfian Hadi, Y. (2020). Penanaman Nilai Nasionalis Melalui Pembelajaran Budaya Lokal Sasak Di Sekolah Dasar. Jurnal Didika: Wahana Ilmiah Pendidikan Dasar, 6(1). Https://Doi.Org/10.29408/Didika.V6i1.2027

DKK, A. P. P. (2014). Korelasi Kebudayaan \& Pendidikan (Membangun Pendidikan Berbasis Budaya Lokal). Jakarta: Yayasan Pustaka Obor Indonesia.

Fauziyah M., S. (2015). Faktor Sosiokultural Dalam Pemakaian Bahasa. Jurnal Pemikiran Islam, 1(1). Http://Download.Garuda.Ristekdikti.Go.Id/Article.Php?Article=809866\&Val=13227\&Title=Faktor\%20 sosiokultural\%20dalam\%20pemakaian\%20bahasa

Ghafor, O. F. (2020). Exploring The Perceptions Of Kurdish EFL University Students Towards Culture As The Fifth Language Skill. Studies In English Language And Education, 7(1). Https://Doi.Org/10.24815/Siele.V7i1.15813

Moleong, Lexy J. (2006). Metodeogi Penelitian Kualitatif. Bandung: Remaja Rosdakarya.

Murdiyati, S. (2020). Peranan Bahasa Indonesia Dalam Membangun Karakter Generasi Muda Bangsa. Journal Of Education Research, 2(3). Https://Doi.Org/10.36653/Educatif.V2i3.21

Novitawati, N., \& Anggreani, C. (2021). Pengembangan Perencanaan Pembelajaran Bermuatan Budaya Lokal Tepian Sungai Pada Anak Usia Dini. Jurnal Obsesi: Jurnal Pendidikan Anak Usia Dini, 6(1). Https://Doi.Org/10.31004/Obsesi.V6i1.767

Prihastari, E. B., \& Widyaningrum, R. (2021). Integrasi Budaya Lokal Dalam Pengembangan LKPD Untuk Mewujudkan Gerakan Literasi Sekolah. Mendidik: Jurnal Kajian Pendidikan Dan Pengajaran, 7(1), 4349. Http://Jm.Ejournal.Id/Index.Php/Mendidik

Sayuti, S. A. (2016). Pemartabatan Dan Pemberadaban Bangsa Melalui Bahasa Dan Sastra. Metafora: Jurnal Pembelajaran Bahasa Dan Sastra, 2(2). DOI: 10.30595/Mtf.V2i2.166

Suhaeb, L. A. S. (2010). Memaknai Budaya Lokal Dan Global Dalam Pengajaran Bahasa Asing. Lingua Didaktika: Jurnal Bahasa Dan Pembelajaran Bahasa, 3(2). Https://Doi.Org/10.24036/Ld.V3i2.7375

Susanto. (2020). Is Intercultural Awareness Reflected In The Classroom? Voices From International Conference For EFL Teachers. Asian ESP Journal, 16(1-2).

Susanto, T. T., Atmaja, J., Nurdiansyah, C., \& Alam, N. (2019). Mengungkap Fenomena Bahasa Campuran Pada Budaya Populer Dalam Perspektif Postmodern. Jurnal Trias Politika, 3(2). Https://Doi.Org/10.33373/Jtp.V3i2.2288

Suyitno, I. (2017). Aspek Budaya Dalam Pembelajaran Bahasa Indonesia Bagi Penutur Asing (BIPA). Bahasa Dan Sastra Indonesia Dalam Konteks Global, 0812178003(1). 
3757 Persepsi Guru Sekolah Dasar terhadap Integrasi Budaya pada Pembelajaran Bahasa Indonesia - Rani Darojah

DOI: https://doi.org/10.31004/edukatif.v3i6.1202

Thanasoulas, D. (2001). Radical Pedagogy ( 2001 ) The Importance Of Teaching Culture In The Foreign Language Classroom. Radical Pedagogy, 7(3). Https://Radicalpedagogy.Icaap.Org/Content/Issue3_3/7Thanasoulas.Html

Triyanto, Fauziyah, F. A., \& Hadi, M. T. (2019). Bahasa Sebagai Pendidikan Budaya Dan Karakter Bangsa. Jurnal Salaka, 1(1). DOI: 10.33751/Jurnal Salaka.V1i1.1145

Vernier, S., Barbuzza, S., Giusti, S. D., \& Moral, G. D. (2008). The Five Language Skills In The EFL Classroom. Nueva Revista De Lenguas Extranjeras, 10, 263-291. Https://Core.Ac.Uk/Download/Pdf/61883904.Pdf

Yanuar, B. A., Suwandi, S., \& Sahid, T. W. (2017). Revitalisasi Peran Budaya Lokal Dalam Materi Pembelajaran Bahasa Indonesia Bagi Penutur Asing (BIPA). ELIC. Http://Jurnal.Unissula.Ac.Id/Index.Php/ELIC/Article/View/1318 